فصلنامه گياهان دارويى

بررسى اثر استشاق اسانس نعناع فلفلى بر اضطراب و دقت دانشجويان يرستارى در بخش اورزانس ويزه بيمارستانهاى آموزشى بيرجند

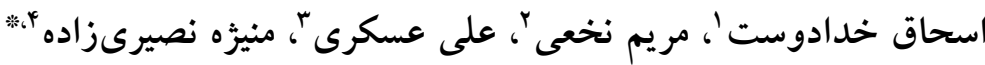

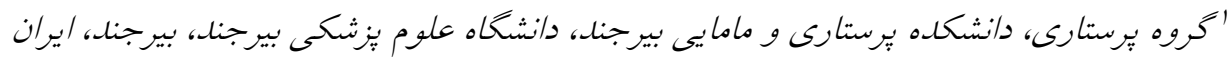

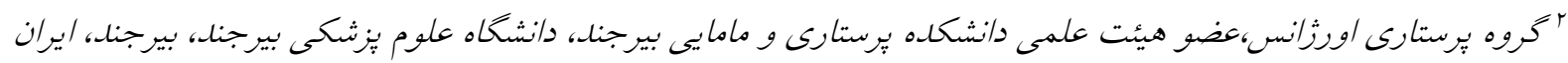

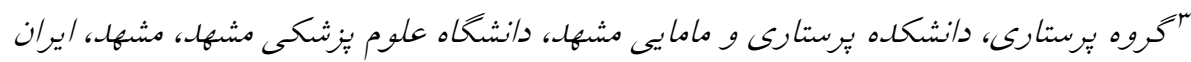

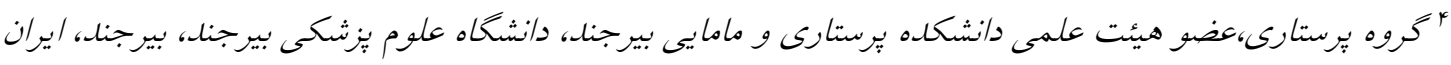

\begin{tabular}{|c|c|}
\hline جكيده & اطلاعات مقاله \\
\hline مقدمه: دقت داشتن و عدم اضطراب دو عامل مهم در نحوه كار دانشجويان يرستارى مىباشد. براى كاهش & 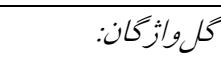 \\
\hline اضطراب و افزايش دقت راههاى متفاوتى از جمله رايحه درمانى ييشنهاد شده است.هدف: اين مطالعه با & 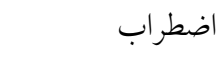 \\
\hline هدف تأثير استنشاق اسانس نعناع فلفلى بر اضطراب و دقت دانشجويان يرستارى در بخش اورزانس ويزه & دقت \\
\hline بيمارستانهاى آموزشى بيرجند انجام شده است. روش بررسى: نوع مطالعه كارآزمايى بالينى مىباشد. يك & رايحه درمانى \\
\hline قطره اسانس نعناع (كروه آزمايش، بr = n) و يك قطره روغن بادام شيرين (دارونما، كT = n) روى كاز & 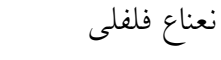 \\
\hline داخل ماسك ريخته و به مدت •r دقيقه در مدت با روز مورد استشاق قرار كرفت. دو يرسشنامه دقت & \\
\hline بوناردل و يرسشنامه اضطراب اشيسلبركر قبل و بعد از مداخله توسط هر دو گروهه ير شد. دادهها با استفاده از & \\
\hline نرمافزار SPSS 22 مورد آزمون قرار كرفت. در مطالعه از آزمونهاى تى تست، تى زوجى، كولمخروف & \\
\hline اسميرنوف، و آزمون كاى دو استفاده شد. نتايج: نتايج اين مطالعه نشان داد كه از نظر متغيرهاى دمو كرافيك & \\
\hline هر دو كروه همسان هستند. نتيجه آزمون تى زوجى در مقايسه ميانكين نمره اضطراب در دو كروه اختلاف & \\
\hline معنى دارى قبل و بعد از مداخله نشان نداد (ه••P> P و همجنين ميانكين نمره دقت بعد از مداخله به طور & \\
\hline 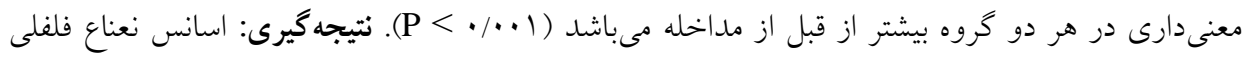 & \\
\hline به نسبت كروه دارونما توانست باعث افزايش دقت دانشجويان يرستارى شود كه با يافتهاى مطالعات ديكر & \\
\hline 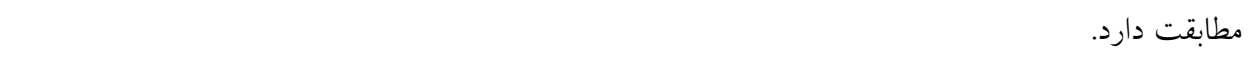 & \\
\hline
\end{tabular}

doi: $10.29252 / \mathrm{jmp} .19 .75 .132$

m.nassirizadeh@yahoo.com:ويسنده مسؤول*

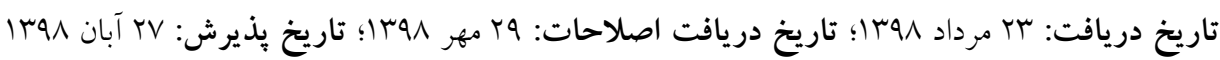
(O) 2020. Open access. This article is distributed under the terms of the Creative Commons Attribution-NonCommercial 4.0 International License (https://creativecommons.org/licenses/by-nc/4.0/) 


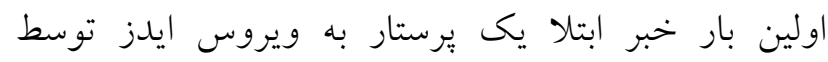

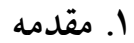

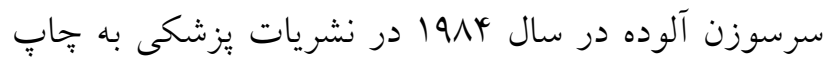

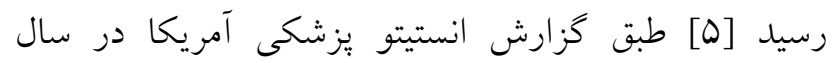

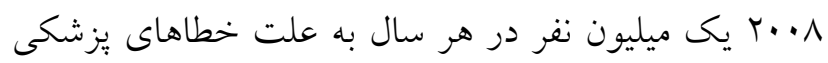

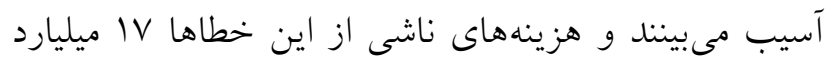

دلار در سال است [9]. يرستاران در ارتباط مستقيم با بيماران هستند بنابراين

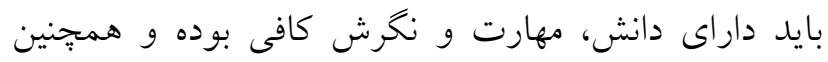

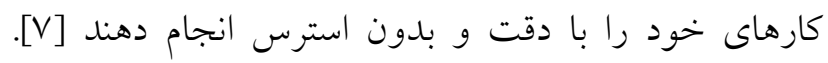

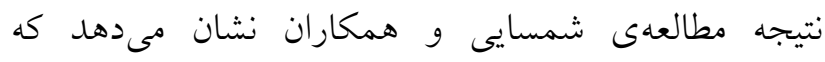

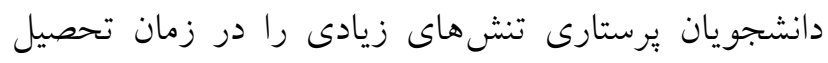

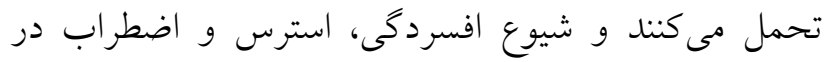

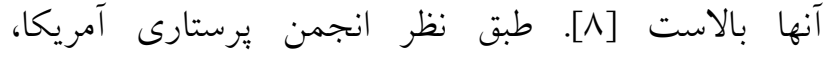

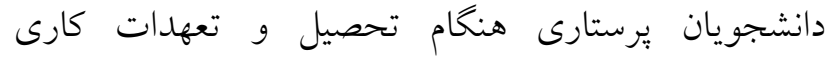

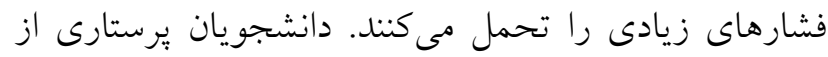

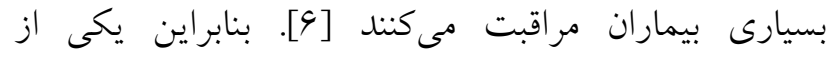
شايعترين مشكلاتدانشجويان يرستارى در محيط بالينى نيز،

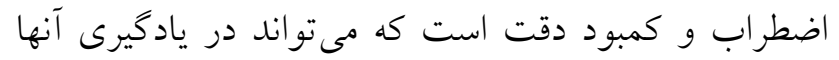

اثرات منفى ايجاد نمايد [9].

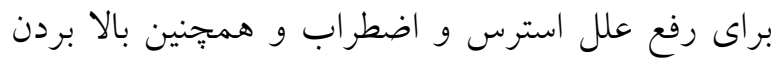

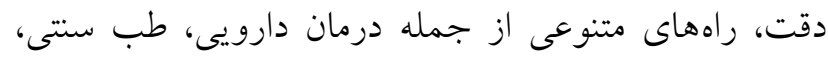

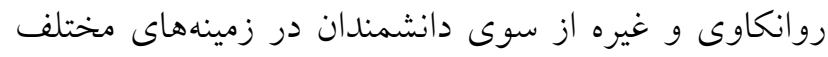

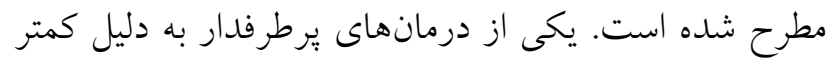

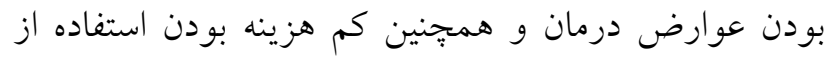

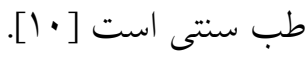
امروزه طب سنتى و مكمل در سطح جهانى كسترش ييدا كرده است و تخمين زده مى شود كه در جهان يك نفر از هر سه نفر براى درمان ناخوشىهاى معمول خوده مثل فئل اضطراب و افسردگى از درمانهاى طب سنتى سنى استفاده مى كند [11]. يكى از روشهراى رايج در طب سنتى استفاده

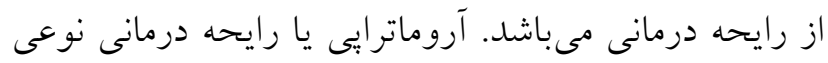
اضطراب به عنوان يك عامل روانى و ايجاد زمينه

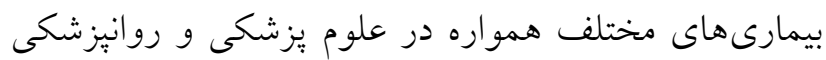
به عنوان يكى موضوع مهم و اساسى مطرح بوده است.

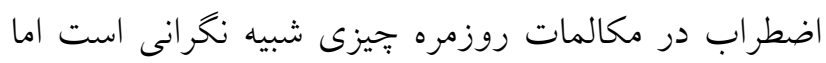

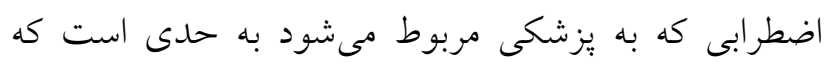

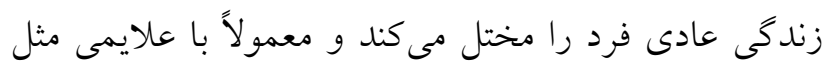

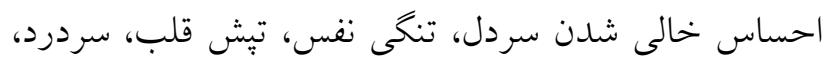

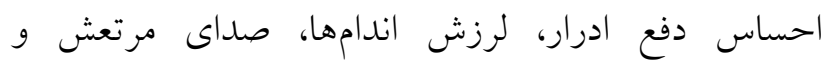

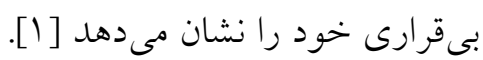

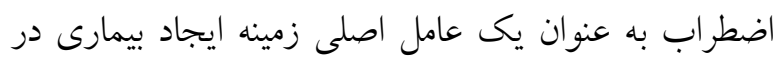

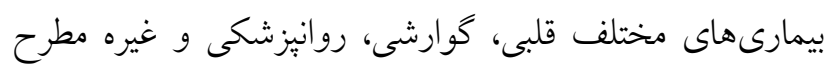

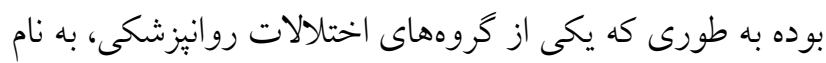

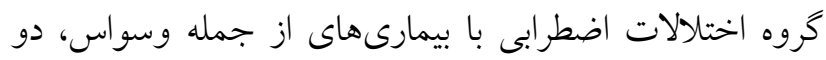
قطبى و غيره طبقهبندى شده است [r]

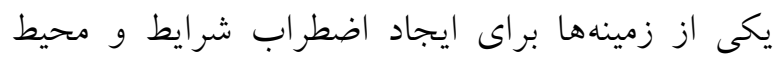
در گير بالاخص ماهيت و محيط شغلى فرد است. شغل فرد ردان هم به دليل ماهيت و هم به دليل محيط مى تواند اضطراب

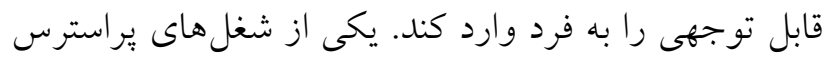

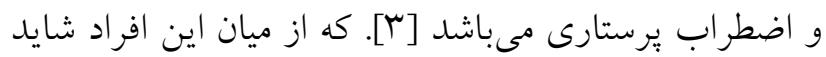

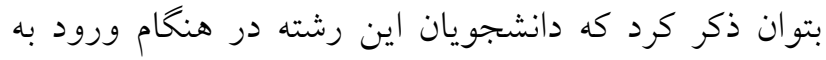

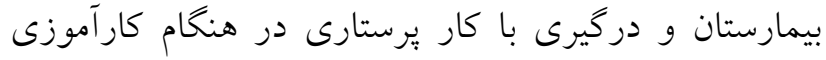

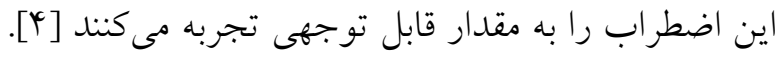

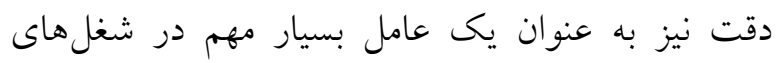

بالينى بالاخص شغل حساس يرستارى كه با جان انسانها

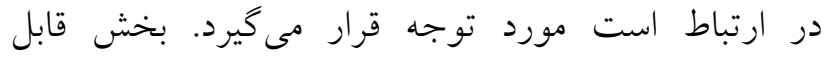
توجهى از اشتباهات خطاهاى بشر معلول بـدوقتى است.

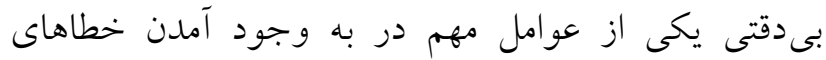

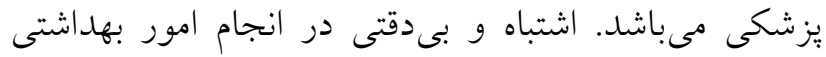

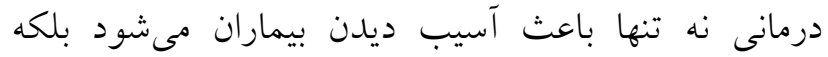

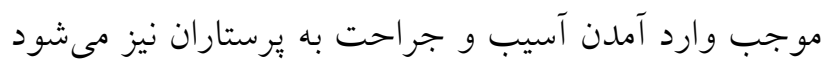


آسم برونشيال، كوليت و رينيت آلرزيك بسيار مؤثر است.

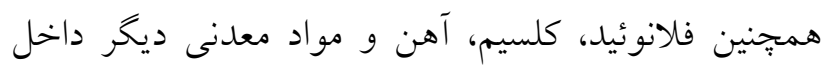

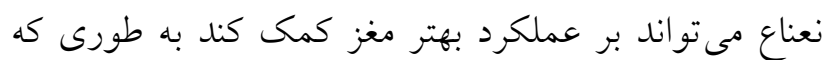

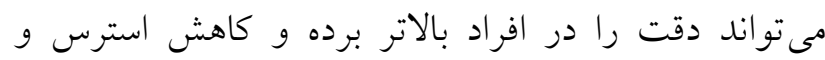

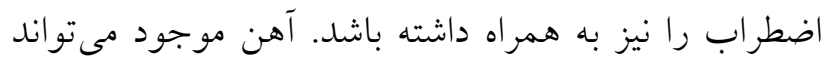

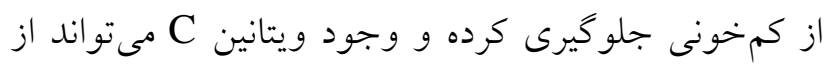

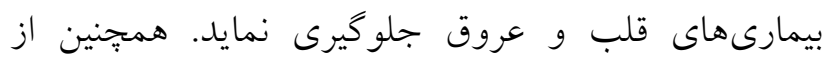

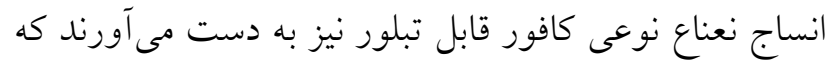

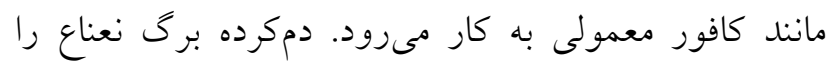

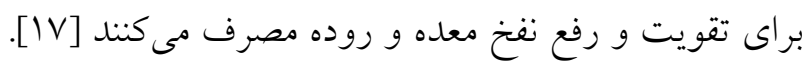

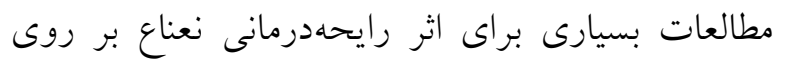

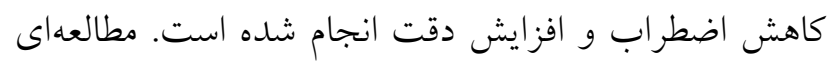

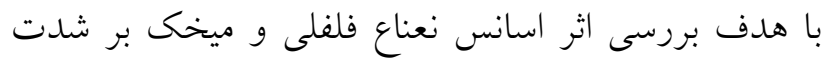

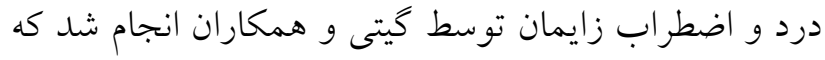
به كاهش اضطراب توسط دو رايحه به صورت من معنادارى منجر شد [1N]. همجنين در مطالعهاى ديكر كه توسط قدس

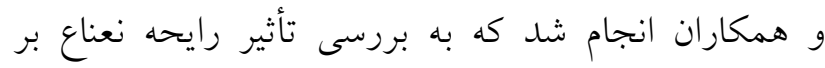

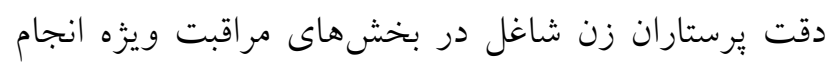

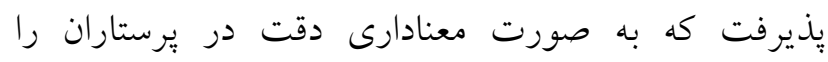

$$
\text { افزايش داده بود [1 الب]. }
$$

با توجه به اثرات مخرب اضطراب و ايجاد زمينهى

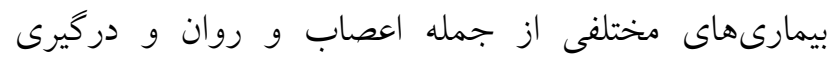

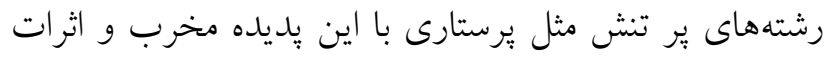

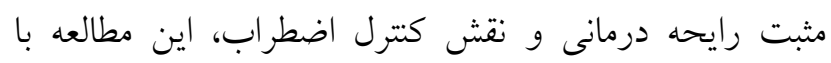

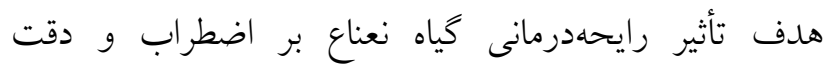
دانشجويان يرستارى در بخش اورزانس ويزه انجام شد.

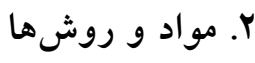

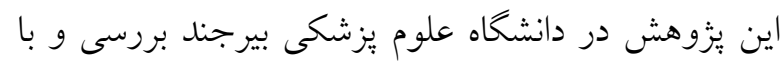

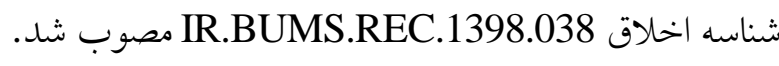

درمان است كه با استفاده از عطر و بويى كه از عصاره

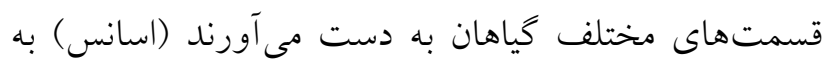
درمان جسمى و روحى افراد، تغيير خلق، عملكرد شناختى دمانى

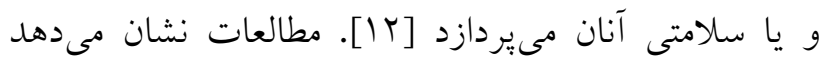

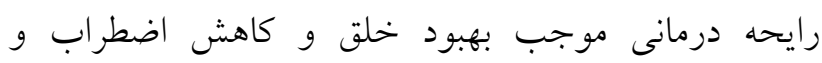

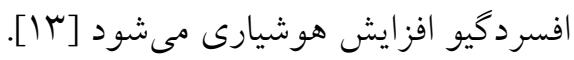

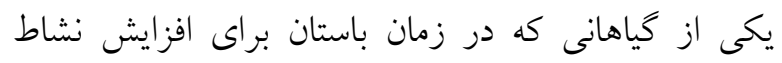

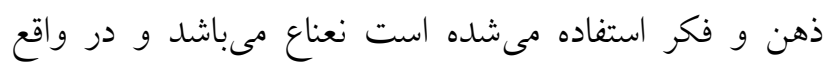

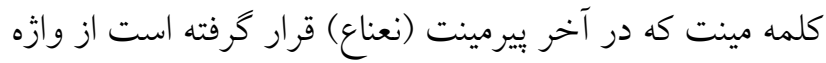
لاتين مينت به معنى فكر كرفته شده است. كياه نعناع مى مواند موجب كاهش نبض، فشار خون و تنظيم ضربان قلب نيز شود

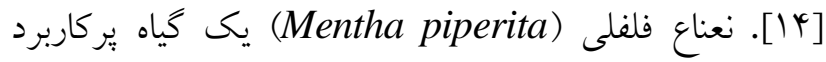
هيبريد است كه علاوه بر ارويا در اكثر نواحى معتدل دنيا نيز

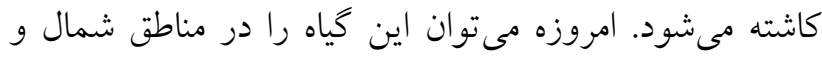
شمال شرق و برخى از ساير نقاط ايران يافت نمود [10].

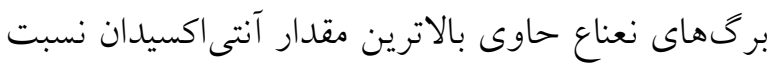

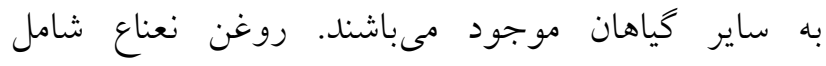

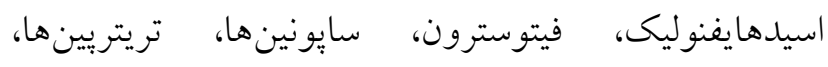

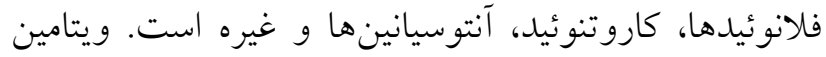

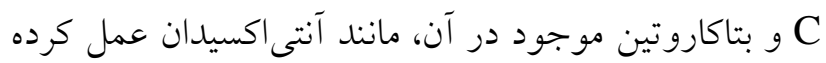

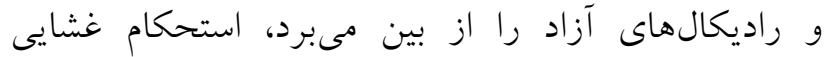

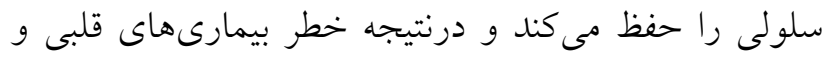

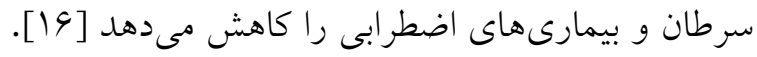

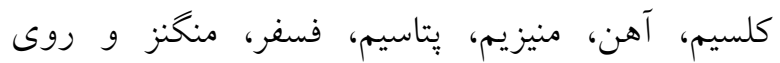

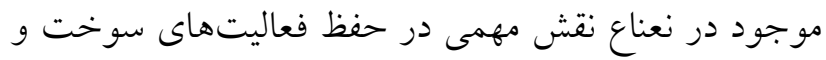

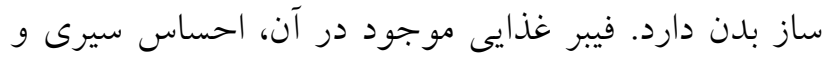
سلامتى رودهاى ايجاد مى كند و يبوست و بواسير را تسكين

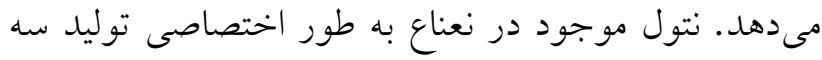

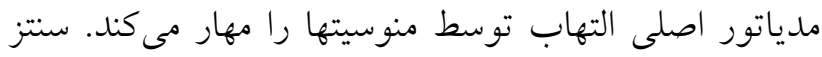

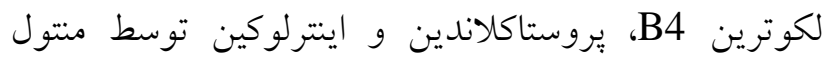

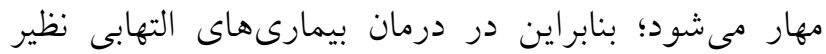


قبل از مداخله يرسشنامهها توسط دانشجويان تكميل شد. سبس به روى كازى كه در داخل ماسك قرار كرفت يكى قطره

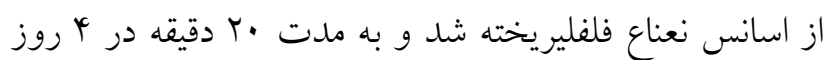

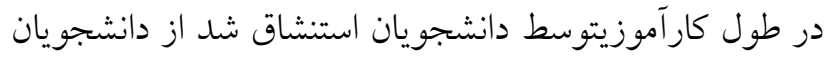
خواسته شد كه در روزهاى مداخله از عطر و ادكلن استفاده

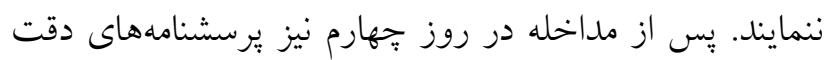

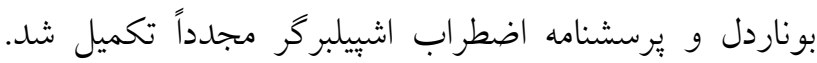

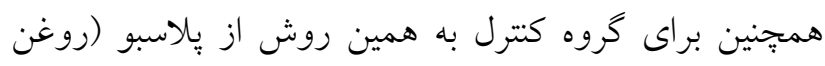

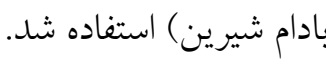

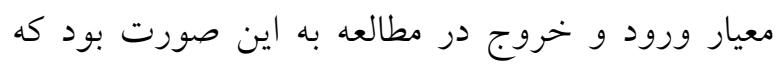

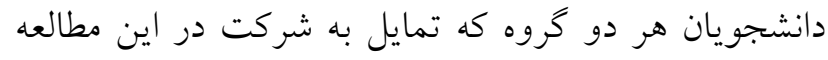

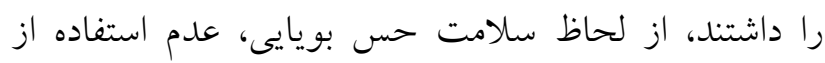

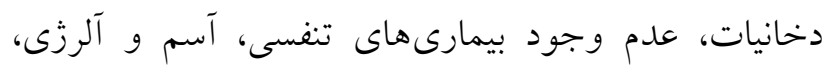

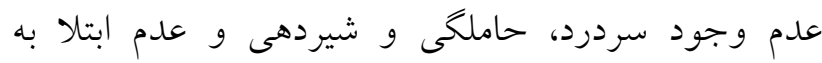

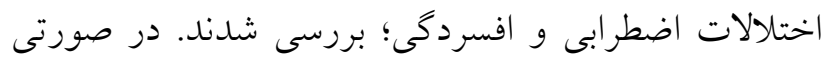

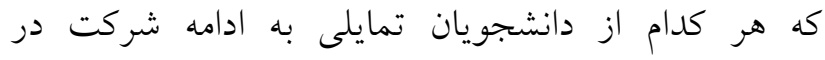

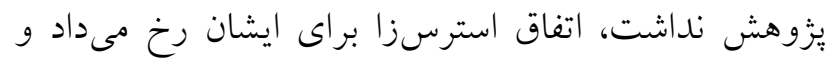

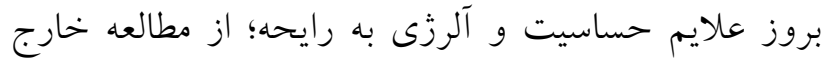

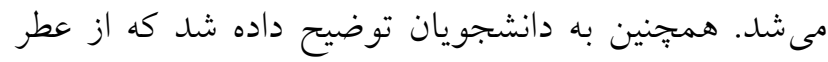
يا ادكلن در روزهاى يزوهش استفاده ننمايند.

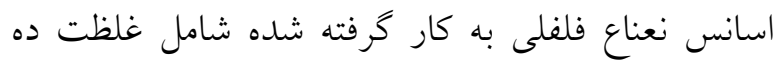

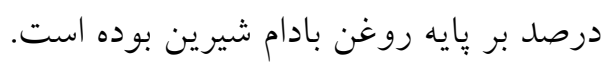

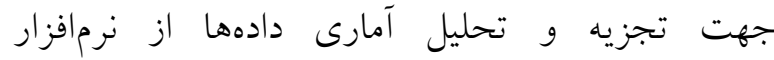

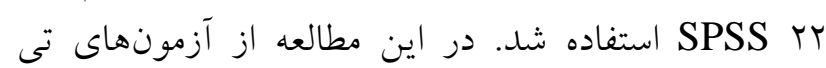

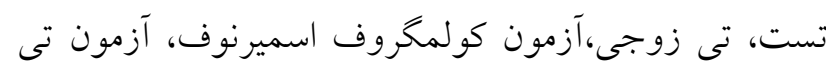

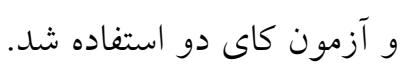

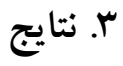

در افراد مورد مطالعه هيجِ گونه سابقه قبلى بيمارى از

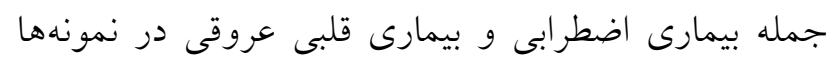

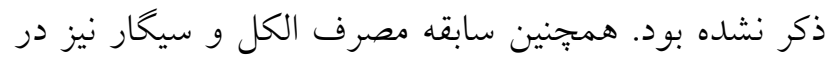

نوع مطالعه از نوع كار آزمايى بالينى مىباشد. جمعيت مورد

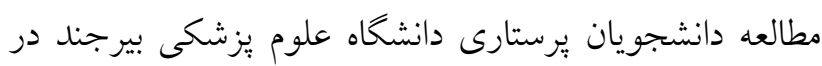

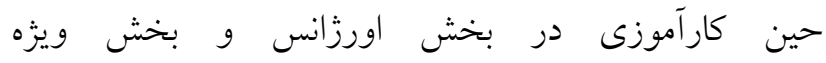

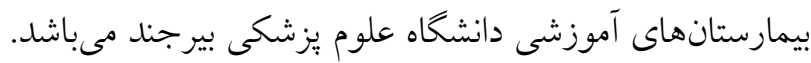

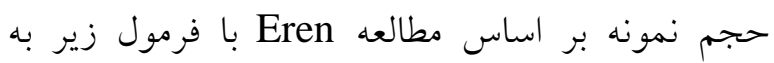
دست آمده است [19].

$$
n=\frac{\left(z_{1-\frac{\alpha}{2}}+z_{1-\beta}\right)^{2}\left(\sigma_{1}{ }^{2}+\sigma_{2}{ }^{2}\right)}{\left(\mu_{1-} \mu_{2}\right)^{2}}
$$

حجم نمونه rr نفر براى گروه آزمايشى و كب نقر كروه

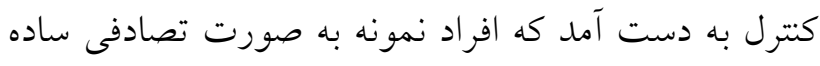
انتخاب شدند.

جهت نمونه گيرى با كمى آموزش دانشكده يرستارى

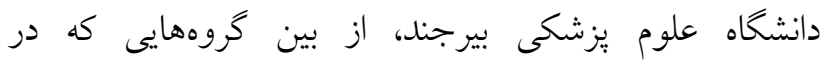

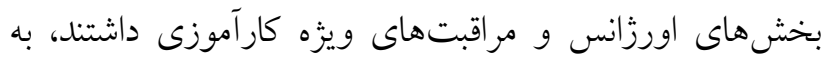

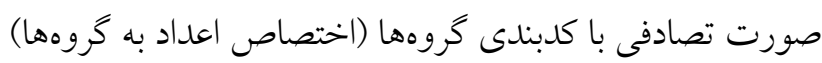

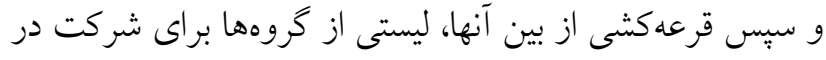

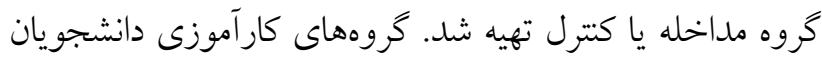

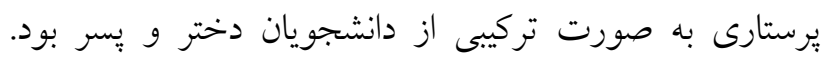

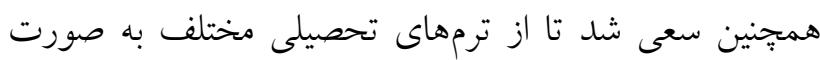

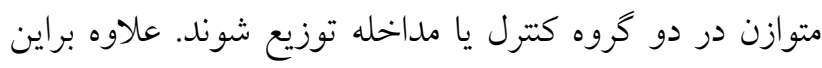

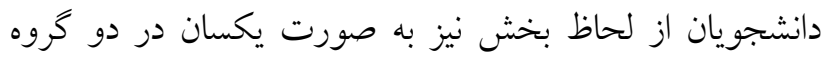

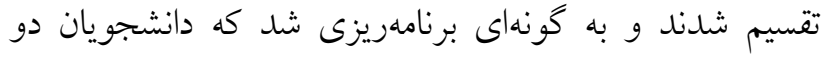

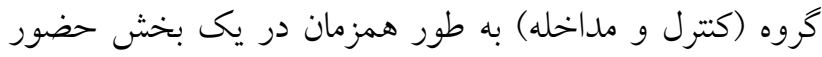
نداشته باشند. ابزار جمعآورى اطلاعات استفاده شده در اين مطالعه دو باتند

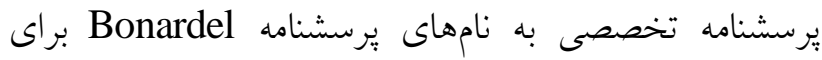

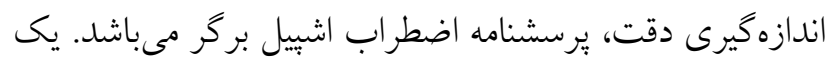

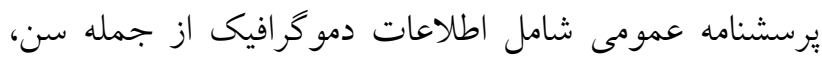

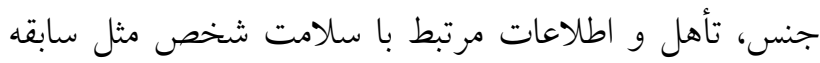
قبلى بيمارى و مصرف سيخار و الكل و غيره استفاده شد. 
هيجيك از افراد مورد مطالعه وجود نداشت. به دليل نبود داد كه جنسيت در دو گروه تفاوت معنى دارى نداشت

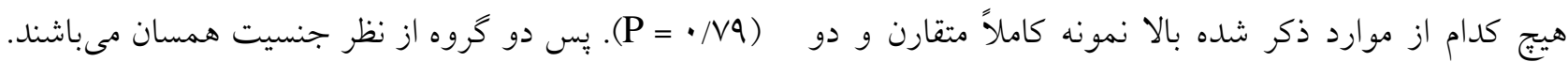

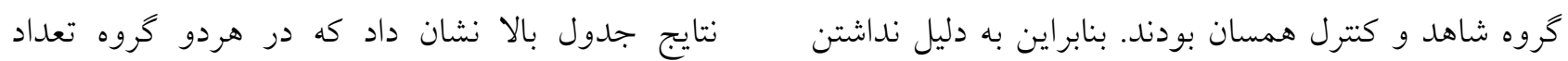

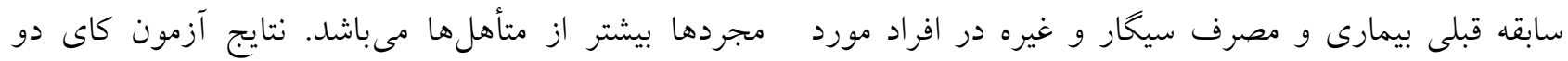

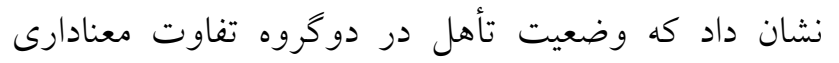

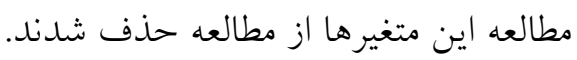

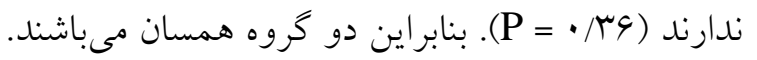

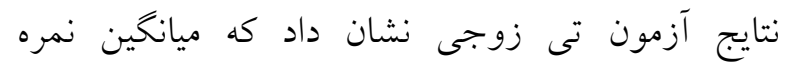

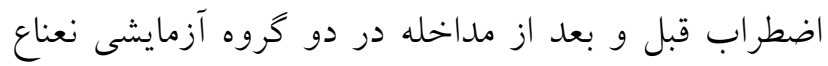
قبل و بعد از مداخله اختلاف معنادارى با يكديكر ندارند

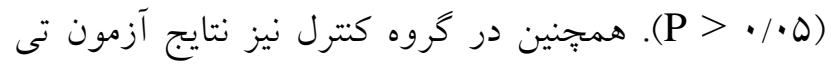

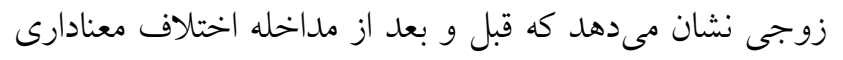

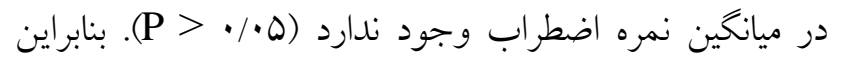

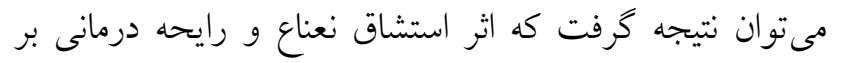

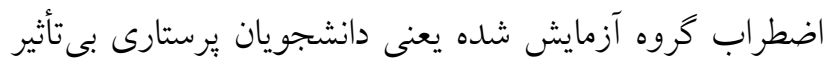

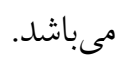
نتايج آزمون تى زوجى نشان داد كه ميانخين نمره دقت

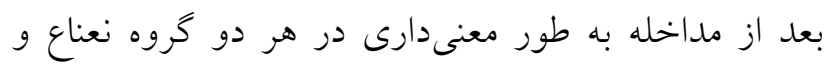
در جداول زير تحليل و مقايسه متغيرهاى دموگرافيك،

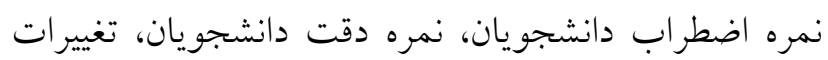
نمره اضطراب دانشجويان و تغييرات نمره دقت دانشجويان در كروههاى مختلف و قبل و بعد از مداخله آمده است

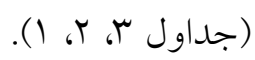
با توجه به جدول بالا و نتيجه آله آزمون كلمخروف

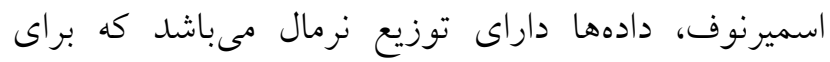

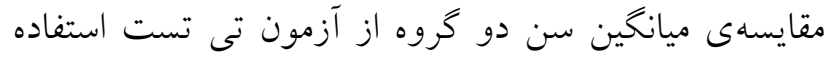

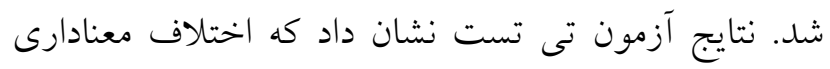
بين سن كروه آزمايش و كنترل وجود ندائ ندارد.

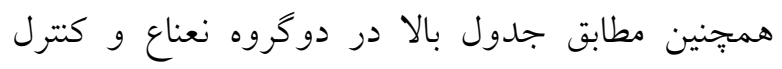

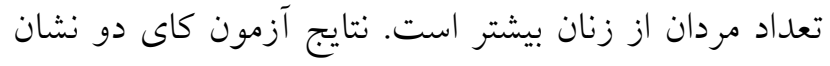

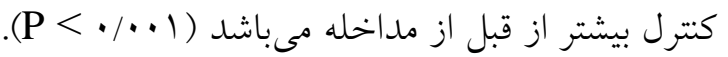

جدول ا. مقايسه متغيرهاى دموكرافيك (سن، جنس و وضعيت تأهل) دانشجويان تحت مطالعه در دو كروه، نعناع و كنترل

\begin{tabular}{|c|c|c|c|c|}
\hline نتيجه آزمون & كنترل & نعناع & & \\
\hline$\chi^{2}=\cdot / \uparrow V$ & $19(9$ (هوره/4) & 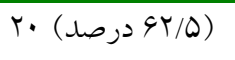 & مرد & \multirow{2}{*}{ جنسيت } \\
\hline $\mathrm{P}=\cdot / \mathrm{V} q$ & W & IY (Y د & زن & \\
\hline$\chi^{2}=r / \cdot 9$ & $r \wedge(1$ ( $1 \wedge V / Q)$ & 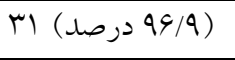 & مجرد & \multirow{2}{*}{ وضعيت تاهل } \\
\hline $\mathrm{P}=\cdot \mu_{4}$ & 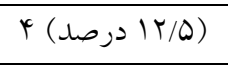 & I (الب درصد & متاهل & \\
\hline $\begin{array}{l}\mathrm{F}=\cdot / \Delta r \\
\mathrm{P}=\cdot / 44\end{array}$ & ו ו ו & $r r / 91$ & ميانكين & \multirow[t]{2}{*}{ سن سن } \\
\hline $\mathrm{K}-\mathrm{S}=\cdot / \mu \Lambda$ & $r / 9 r$ & $T / T Q$ & انحر اف معيار & \\
\hline
\end{tabular}


جدول r. مقايسه ميانكين نمره اضطر اب دانشجويان تحت مطالعه در دو گروه قبل و بعد از مداخله

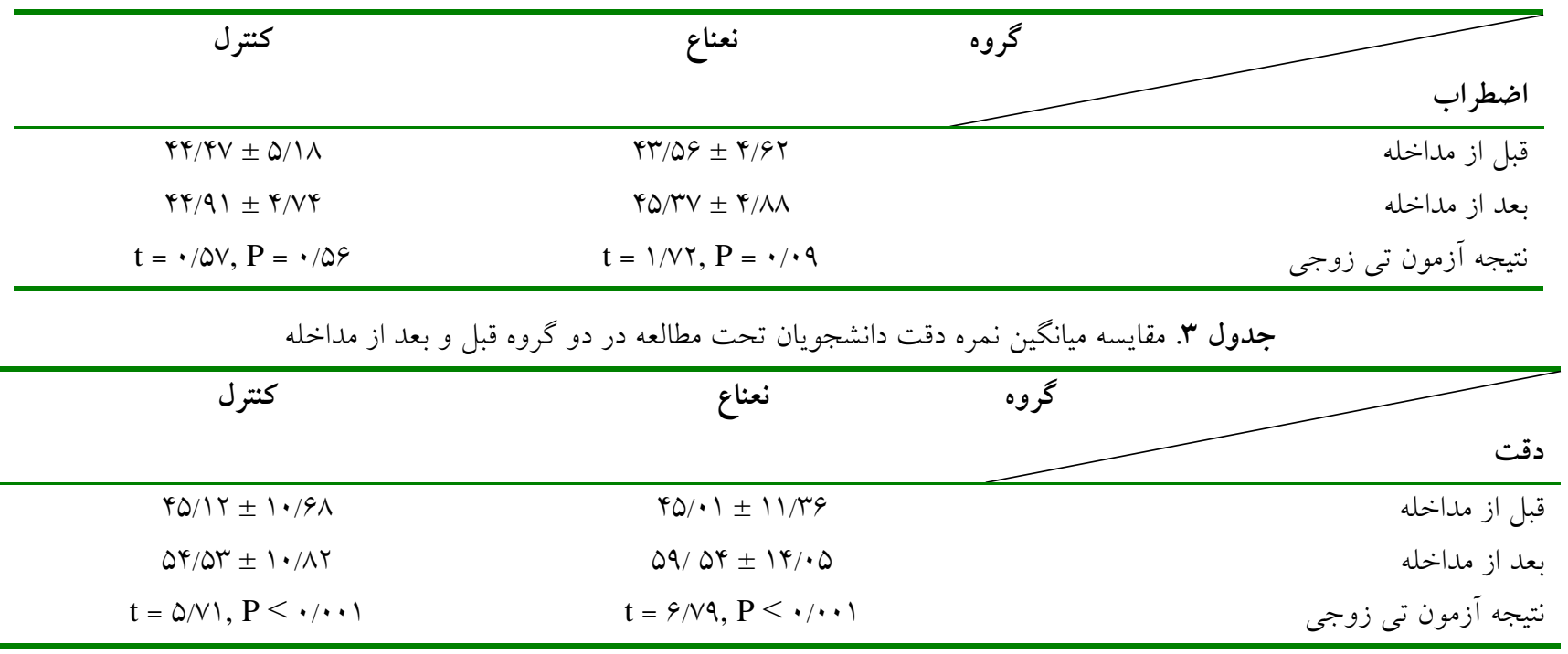

دانشجويان علوم بزشكى تهران غيرهمسو مىباشد [•r]. اين

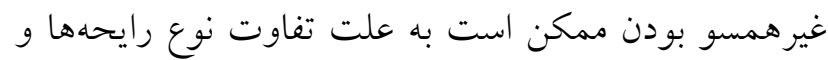

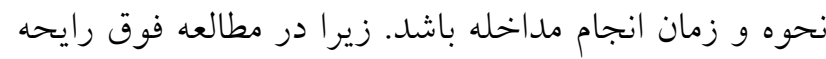

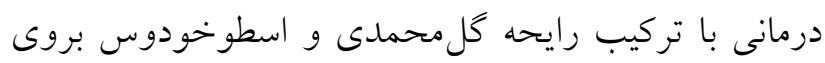

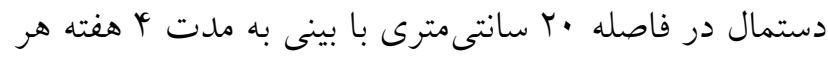

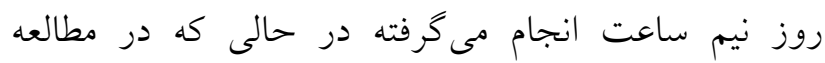

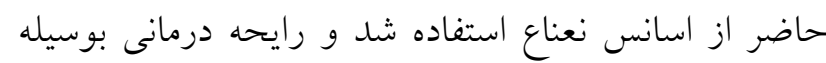
ماسك و با روز هر روز •r دقيقه انجام شده است.

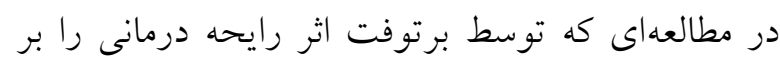

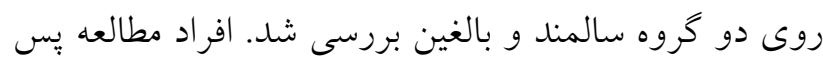

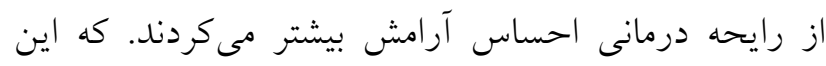

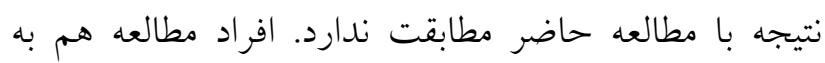
دليل بيمار بودن و هم تفاوت شرايط سنى ماصنه با افراد مورد

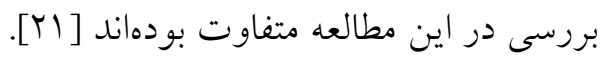

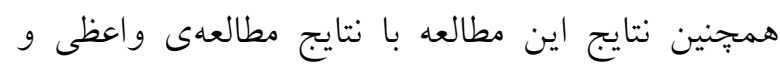

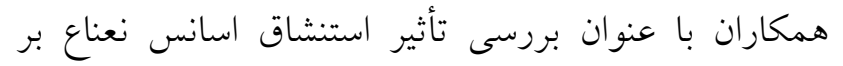

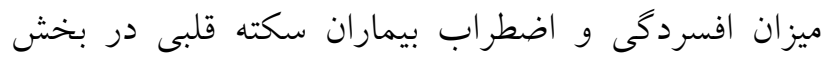
مراقبت ويزه قلبى در بيمارستانهاى سيرجان مطابقت نداب لدارد

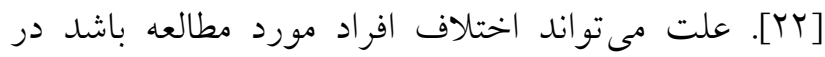

اين مطالعه با هدف تأثير استشاق رايحه نعناع بر

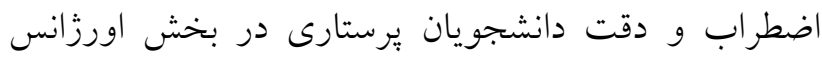
ويزه بيمارستانهاى آموزشى بير جند انجام شد.

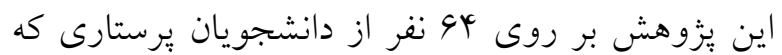

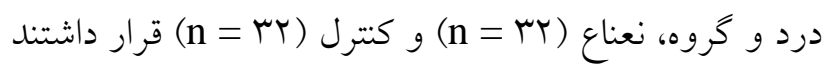
انجام و نمره اضطراب و دقت دروه آنها مورد ارزيابى قرار

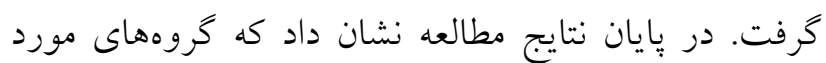

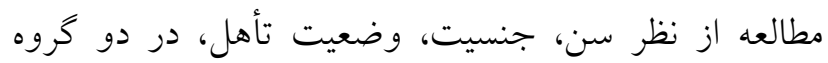

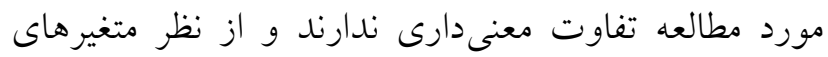
دموكرافيك دو كروه نعناع و كنترل همسان بودند. هم:نينين

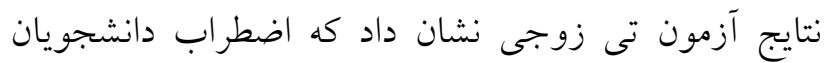
قبل و بعد از مداخله به صورت معنادارى تغيير نكرده است نقان

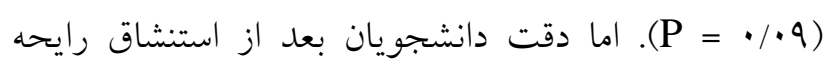
نعناع بيشتر شده است (P) (P)

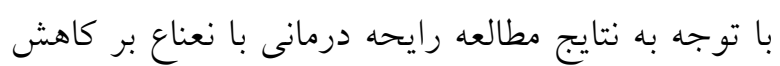

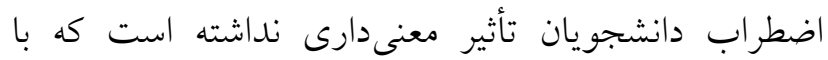
نتايج مطالعه صاحب الزمانى و همكاران در سال 19 با عنوان

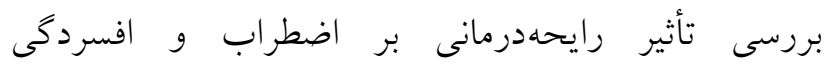




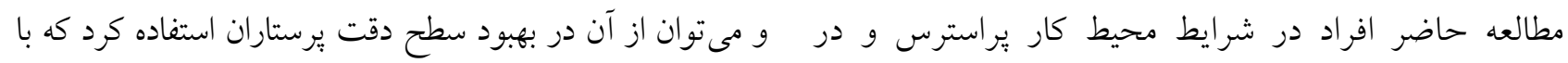

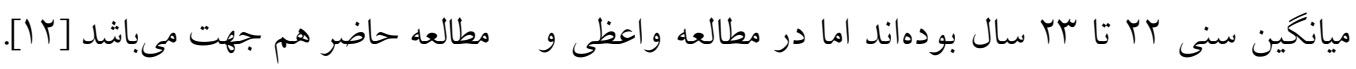

\section{ه. نتيجه كيرى}

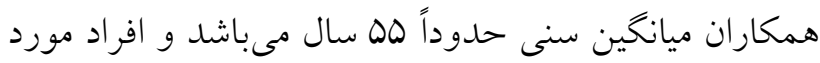

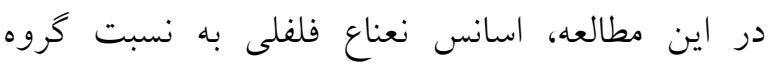

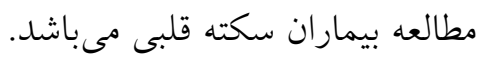

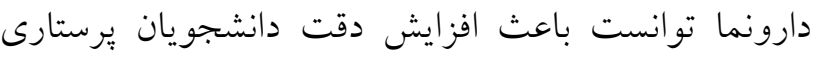
در مطالعه ديخر، تأثير استنشاق رايحه نعناع فلفلى بر درد

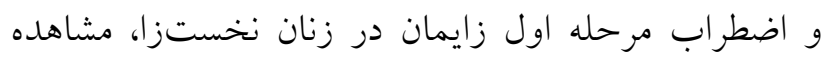

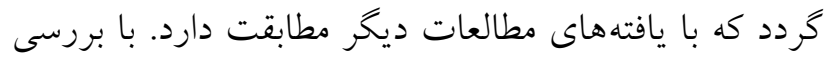

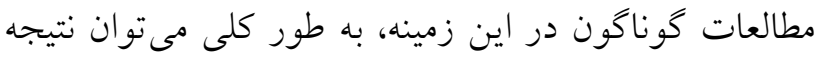

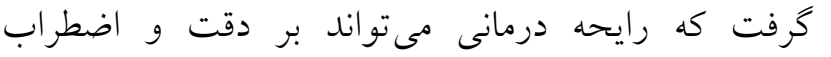

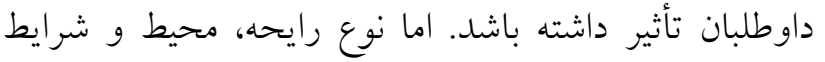
استفاده از آن نيز تأثير كذار مىباشد. باسل

مشار كت نويسند اين مقاله بركرفته از يايان نامه نويسنده اول،استاد راهنما

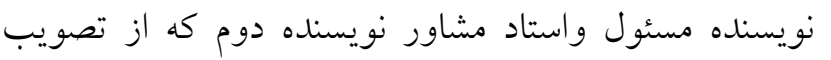

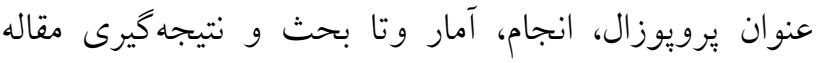

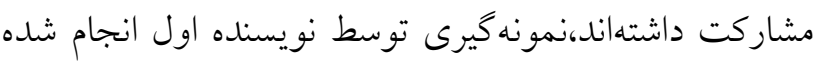
ونويسنده سوم همكارى در آمار ونتيجه كيرى ونوشتن مقاله

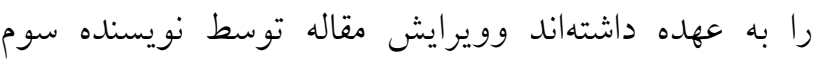
ومسئول انجام شده است. تأييد مقاله توسط هر جهار نويسنده انجام شده است.

تضاد منافع نويسندكان اعلام مىكند كه هيجگ كونه تضاد منافعى وجود

\section{تقدير و تشكر}

نويسندكان مقاله بدينوسيله از معاونت يزوهشيى دانشخاه علوم يزشكى بيرجند به دليل حمايتهاى مالى وتمامى اساتيد و دانشجويان برستارى كه در اين همكارى نمودهاند،صميمانه

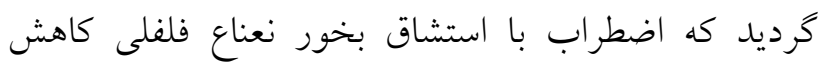

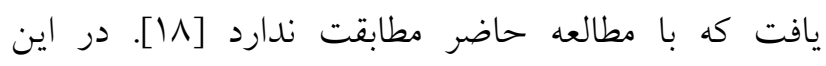

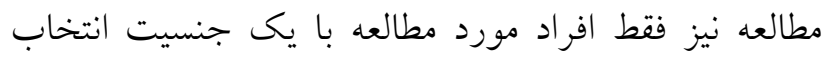

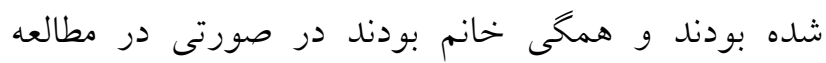

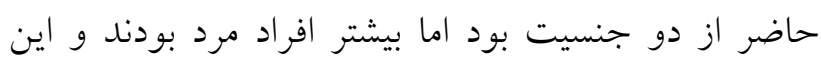
اختلاف جنسيتى مى تواند مسبب اختلاف نتايج مطالعه باشد.

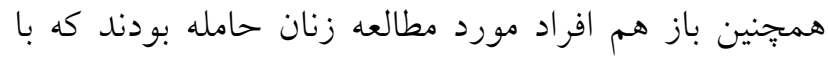

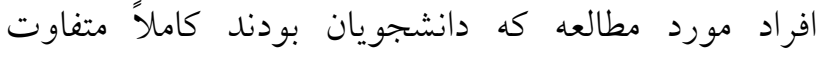
مىباشد. استفاده از رايحه درمانى در مطالعه حاضر نشان داد داد

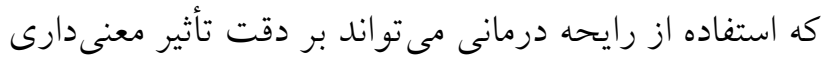
داشته باشد. مطالعهاى با عنوان بررسى نقش رايحهها (رايحه

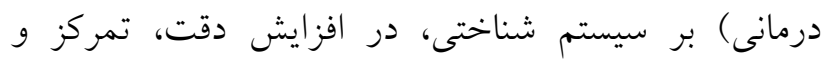
حافظه بر روى צr نقر (دو گروه سا نقره) كه داراى سطح همسان هوش، بينايى، سنى و تحصيلى مشابه بودند انجام شد كه از انواع رايحههاى گياهى توسط دستيكاه اسيرى

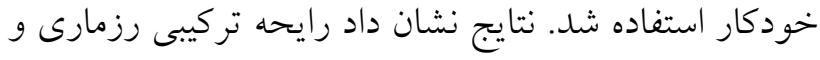

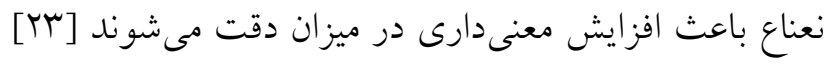

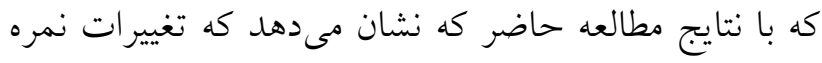

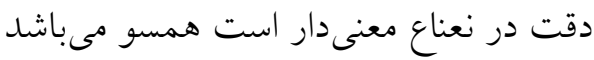

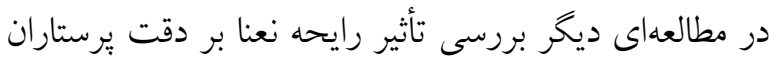

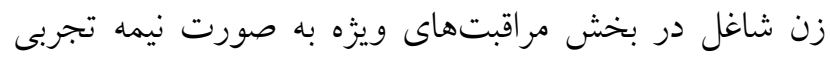

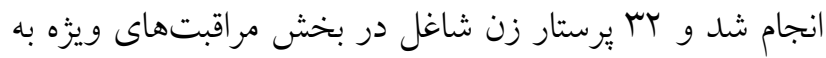
روش نمونه كيرى در دسترس انتخاب شدند. نتايج اين مطالعه نشان داد رايحه نعناع اثرات مثبى بر روى دقت ديرست ديتاران داشته قدردانى مىنمايد. 
1. Ajorpaz NM, Ezadi $A$ and Heidari S. Comparison of routine education and video $\mathrm{CD}$ on anxiety level before general surgery. Qom University of Medical Sciences J. 2014; 8(5): 19-25.

2. Atkinson R, Nolen-Hoeksema $\mathrm{S}$, Fredrickson B, Loftus $\mathrm{G}$ and Lutz C. Atkinson \& Hilgard's Introduction to Psychology. New York: McGraw-Hill; 2004.

3. Zamani N, Barahmand A and Farhadi M. The effects of problem-solving training in reducing anxiety among a group of nursing students. J. Nursing Education. 2017; 6(3): 5661.

4. Komeili-Sani M, Etemadi A, Boustani H, Bahreini $M$ and Hakimi A. The relationship between nurses' clinical competency and job stress in Ahvaz university hospital, 2013. J. Clinical Nursing and Midwifery 2015; 4: 39-49.

5. Ebrahimian A. Night work nursing: The level of attention. 2006.

6. Espelin J and McKelvey M. Stress buster sessions for nursing students. Nursing made Incredibly Easy. 2018; 16(5): 8-11.

7. Abdollahi D. Association of Educational Planning with Mental Health of Nursing Students of Tehran Medical Science University with Emphasis on the Educational Stressor Factors and Stress Management Method. J. Health Education and Health Promotion. 2016; 4(1): 40-9.

8. Shamsaei F, Yaghmaei S, Sadeghian E and Tapak L. Survey of Stress, Anxiety and Depression in Undergraduate Nursing Students of Hamadan University of Medical Sciences. 2018.

9. Bagheriyeh F, Hemmati Maslek Pak M and Hashemloo I. The effect of peer mentoring program on anxiety student in clinical environment. J. Nursing and Midwifery Urmia University of Medical Sciences 2015; 13(8): 648-54.

10. Alavi M, Farokhnekhad $P$ and Daneshvar S. The effect of lavender aroma on stress of nurses working in intensive care units. Cardiovascular Nursing J. 2014; 4(1): 282291.

11. Ghiasi M, Ehsani E and Mahbooboi M. Doesaromatherapy affect anxiety of veteran students? Iranian Journal of War and Public Health. 2012; 4(2): 18-23.

12. Ghods A, Sotodehasl N, GHorbani R and valian M. The Effects of Lavendula Aroma on the Accuracy of Intensive Care Nurses. Journal of Babol University of Medical Sciences 2014; 15(5):161-167.

13. Bahreini, Saina, Naji, Manafi. Aromatherapy and its application. J. Urmia Nursing and Midwifery Faculty 2011; 9(1): 1-8.

14. Najafi Doulatabad S, Hashemi N, Mohebi Nobandegani Z, Sadeghi H, Jafari A, Najafi Doulatabad A and et al. The effect of Hydroalcoholic Extract of Mentha piperita (Complement Treatment) on Severity of Depressed Patients. Armaghane Danesh 2009; 14(3): 83-90.

15. Abdolmaleki A, Rajabi A and Sanginabadi F. Evaluation of the analgesic and antiinflammatory effects of aqueous extract of peppermint (Mentha piperita). Scientific Journal of Kurdistan University of Medical Sciences. 2013; 18(1): 67-74.

16. Zargari A. Medicinal Plants. 8, editor. Tehran: University of Tehran; 2010.

17. Juergens U, Stöber $M$ andVetter $H$. The anti-inflammatory activity of L-menthol 
compared to mint oil in human monocytes in vitro: a novel perspective for its therapeutic use in inflammatory diseases. European J. Medical Res. 1998; 3(12): 539-45.

18. Azgoli G, Tarkashvand S, Salehimoghadam F, Boromandnia N, Mojab F and Minooie S. Comparison of carnation essential oil and peppermint essential oil on pain and anxiety of first stage of labor. The Iranian Journal of Obstetrics, Gynecology and Infertility 2016; 19(21): 1-11.

19. Nadiye Baris Eren MSc R, Gursel Oztunc $\mathrm{PhD}$ R. The effects of aromatherapy on the stress and anxiety levels of nurses working in intensive care units. International Journal of Caring Sciences 2017; 10(3): 1615-23.

20. Sahebzamani M, Khanavi M, Alavimajd H, Mirkarimi $M$ and Karimi M. The effect of inhaled aromatherapy on anxiety and depression of female students living in dormitory of Tehran University of Medical Sciences. Medical Sciences Journal of Islamic Azad Univesity - Tehran Medical Branch. 2010; 20(3): 175-181.
21. Bortoft J. Massage for mental health. Therapist-worthing. 1996; 4: 38-9.

22. Vaezi A, Parizi S, Vahidi A and Tavangar H. The Effect of Inhalation of Peppermint Essential Oil on Depression and Anxiety in Myocardial Infarction Patients in Sirjan Hospitals. J. Med. Plants 2016; 16(62): 55-62.

23. Feizipoor $\mathrm{H}$ and Javanmard G. The Role of Aromatherapy on Cognitive System in Increasing Accuracy, Concentration and Memory. First National Conference on Cognitive Science in Education: Ferdowsi University of Mashhad. 2010.

How to cite this article: Khodadost E, Nakhaei M, Askari A, Nasirizade M. The effect of inhalation of peppermint essential oil on anxiety and acurracy of nursing students in emergency department of Birjandeducational hospitals. Journal of Medicinal Plants 2020; 19(75): 132-140.

doi: 10.29252/jmp.19.75.132 
Journal of Medicinal Plants

Institute of

Medicinal Plants

Journal homepage: $\underline{w w w . j m p . i r}$

Research Article

\title{
The effect of inhalation of peppermint essential oilon anxiety and acurracy of nursing students in emergency department of Birjand educational hospitals
}

\author{
Eshagh Khodadost ${ }^{1}$, Maryam Nakhaei ${ }^{2}$, Ali Askari ${ }^{3}$, Manizhe Nasirizade, , $^{*}$ \\ ${ }^{1}$ Department of Emergency Nursing, School of Nursing and Midwifery, Birjand University of Medical \\ Sciences, Birjand, Iran \\ ${ }^{2}$ Assistant Professor of Nursing, Department of Emergency Nursing, School of Nursing and Midwifery, \\ Birjand University of Medical Sciences, Birjand, Iran \\ ${ }^{3}$ Nursing and Midwifery Care Research Center, Mashhad University of Medical Sciences, Mashhad, Iran \\ ${ }^{4}$ Instructor of Nursing, Department of Nursing, School of Nursing and Midwifery, Birjand University of \\ Medical Science, Birjand, Iran
}

\begin{tabular}{|c|c|}
\hline ARTICLE INFO & ABSTRACT \\
\hline $\begin{array}{l}\text { Keywords: } \\
\text { Accuracy } \\
\text { Anxiety } \\
\text { Aromatherapy } \\
\text { Mint }\end{array}$ & $\begin{array}{l}\text { Background: Accuracy and lack of anxiety are two important factors in how } \\
\text { nursing student's work. Various methods, including aromatherapy, have been } \\
\text { suggested to reduce anxiety and increase accuracy. Objective: The aim of this } \\
\text { study was to investigate the effect of inhaling peppermint essential oilon anxiety } \\
\text { and accuracy of nursing students in emergency department of Birjandeducational } \\
\text { hospitals. Methods: This is a clinical trial study. One drop of peppermint essential } \\
\text { oil (experimental group, } \mathrm{n}=32 \text { ) and one drop of sweet almond oil (placebo, } \\
\mathrm{n}=32 \text { ) was poured on the gauze into the mask and inhaled for } 20 \text { minutes in } 4 \\
\text { days. Both Bonardel Accuracy Questionnaire and Spielberger Anxiety } \\
\text { Questionnaire were completed by both groups before and after the intervention. } \\
\text { Data were analyzed using SPSS } 22 \text { software. The study used t-test, paired t-test, } \\
\text { Kolmogorov-Smirnov test, and chi-square test. Results: The results of this study } \\
\text { showed that both groups were similar in terms of demographic variables. Paired t- } \\
\text { test showed no significant difference between the two groups before and after the } \\
\text { intervention (P < 0.05). Paired t-test results showed that the mean score of } \\
\text { accuracy after the intervention was significantly higher in both groups (P < } 0.001 \text { ). } \\
\text { Conclusion: Peppermint essential oil compared to the placebo group was able to } \\
\text { increase the accuracy of nursing students, which is consistent with the findings of } \\
\text { other studies. }\end{array}$ \\
\hline
\end{tabular}

* Corresponding author: m.nassirizadeh@yahoo.com

doi: $10.29252 / \mathrm{jmp} .19 .75 .132$

Received 14 August 2019; Received in revised form 21 October 2019; Accepted 18 November 2019

(C) 2020. Open access. This article is distributed under the terms of the Creative Commons Attribution-NonCommercial 4.0 International License (https://creativecommons.org/licenses/by-nc/4.0/) 